\title{
Quality Evaluation of Fibre- Enriched Bread
}

\author{
Ibidapo Phebean Olubunmi*, Kosoko Sulaimon Babatunde, Oluwole Oluwatoyin Bolanle, \\ Saliu Olumide Seyioba, Latona-Tella Taiwo, Oloruntumise Ayodele Olukayode, \\ Elemo Gloria Nwankego
}

Department of Food Technology, Federal Institute of Industrial Research, Lagos, Nigeria

Email address:

bunmikaydapo@gmail.com (I. P. Olubunmi)

\section{To cite this article:}

Ibidapo Phebean Olubunmi, Kosoko Sulaimon Babatunde, Oluwole Oluwatoyin Bolanle, Saliu Olumide Seyioba, Latona-Tella Taiwo, Oloruntumise Ayodele Olukayode, Elemo Gloria Nwankego. Quality Evaluation of Fibre- Enriched Bread. International Journal of Nutrition and Food Sciences. Vol. 4, No. 4, 2015, pp. 503-508. doi: 10.11648/j.jinfs.20150404.23

\begin{abstract}
The advocacy on the use of composite cassava-wheat flour for commercial bread making purposes and its consumption had gained ground in Nigeria. This study was carried out to investigate the effect of coconut fiber (CCF)and corn bran $(\mathrm{CBN})$ as sources of dietary fibre at different level of inclusion $(0 \%, 5 \%, 10 \%)$ on the physical, chemical composition and organoleptic qualities of developed bread from composite flour made by mixing cassava and wheat flour at ratio of 10:90 (w/w). Results showed a significant reduction $(\mathrm{p}<0.05)$ in the loaf volume and specific loaf volume of the fibre enriched bread with increased level of fibre inclusion. It ranged from $1250-1403.3 \mathrm{~cm} 3$ and $4.98-5.77 \mathrm{~cm} 3 / \mathrm{g}$ respectively with highest values obtained from 5\% CCF inclusion and the lowest value from 10\% CBN inclusion The dietary fibre content of the bread loaves increased significantly $(\mathrm{p}>0.05)$ as the level of CCF fibre increased. It ranged from 3.79 to $5.28 \%$ with the highest value in $10 \% \mathrm{CCF}$ level and lowest in 10\% CBN fibre bread. However, result indicated that CBN fibre bread had lower dietary fibre contents of 3.79 and $3.98 \%$ compared to the control sample $0 \%(4.56 \%)$. The study revealed that coconut enriched bread with DF of $5.28 \%$ was able to deliver $21.12 \%$ of the Recommended Daily Intake for dietary fibre. Significant reduction existed $(\mathrm{p}<0.05)$ in the moisture content of the CCF fibre bread from 5 to $10 \%$ level of inclusions studied. The crude protein content of the fibre bread samples increased significantly with increasing levels of CCF and CBN fibres and ranged from 4.56 to $5.15 \%$ and the control sample $(4.69 \%)$. The dry matter content of the bread sample showed significant increase in the level of CCF fibre inclusion from 5 to $10 \%$ while on the other hand, it decreased significantly from 5 to $10 \%$ corn bran fibre bread (CBN). It ranged from 66.52 to $69.56 \%$ with the highest value in $10 \%$ CCF fibre level and lowest in control sample of non fibre bread. The mean sensory scores obtained showed no significant ( $p>0.05$ ) difference between 5\% and 10\% coconut fibre enriched bread and 10:90 cassava- wheat bread (CONTROL), however bread with $5 \%$ inclusion had the highest taste, chewability and overall acceptability scores in all the attributes evaluated.
\end{abstract}

Keywords: Composite Flour, Dietary Fibre, Bread, Coconut Fibre, Corn Bran

\section{Introduction}

In the past few years, there has been an increasing consumer interest and awareness in the field of food nutrition as a result of incidence of some diet related- health problems such as obesity, high blood pressure, diabetes, cancer of colon, gastrointestinal disease and cardiovascular disease [1, 2]. This has given rise to increased demand for health oriented and functional food products such as sugar-free, low calorie, low cholesterol and high fibre products. In view of these, development of high fibre products is one of the approaches that can be used to tackle these health problems.
Dietary fibre is the remnants of the edible part of plant and analogous carbohydrates which includes polysaccharides, oligosaccharides, lignin, and associated substances that are resistant to digestion and absorption in the human small intestines with complete or partial fermentation in the human large intestines [3].

Dietary fibre has been shown to have important health implications in the prevention for risk of chronic diseases such as cancer, cardiovascular diseases and diabetes mellitus [4]. Recent studies indicated that dietary fiber (soluble and 
insoluble) helps in preventing cardiovascular diseases, colon cancer and reducing cholesterol [5, 6]. Fiber-rich foods are produced by adding functional fiber or using basic ingredients with high dietary fiber content. Interest in fibreenhanced foods has resulted in the use of wheat bran, refined cellulose, fruits and vegetable skins to enrich target foods such as baked foods, breakfast cereals etc consequently; development of market for fibre-rich products and ingredients has been on the increase $[5,6,7]$

The Academy of Nutrition and Dietetics (AND), previously called ADA recommends a dietary fiber intake of 25-35 g/day for a healthy adult depending on calorie intake. Several researchers have worked on the addition of dietary fibre to breakfast cereals and baked products particularly breads and cookies in order to meet the consumer's health need $[8,9$, and 10$]$.

Bread is the major baked product that is widely acceptable and consumed as a very convenient form of food worldwide; however, there are increasing demands toward consumption of high fibre breads due to their health prompting properties. It is a good source of nutrients, such as macronutrients (carbohydrates, protein and fat) and micronutrients (minerals and vitamins) that are all essential for human health. It is eaten either as a snack as a quick way of quenching hunger or as a main dish, therefore it forms the greater percentage of daily menu especially where convenience food is on the increase. [11]. Coconut (Cocos nucifera) flour is from coconut residue, which is a by- product of coconut milk extraction. It is extremely high in fiber with almost double the amount found in wheat bran [12]. Coconut flour can provide not only value added income to the industry, but also a nutritious and healthy source of dietary fibre [13]. Similarly, it was reported that coconut flour is a significant source of dietary fibre, free of trans- fatty acids and it is low in digestible carbohydrates [14].

Also, upgrading the use of coconut flour and corn bran from animal feed and waste material to functional food ingredients will be of great benefit to meet the food demands and application.

The research work is therefore aimed at developing fibreenriched bread using coconut flour and corn bran flour and optimizing its level of inclusion on the basis of providing up to $20 \%$ of the recommended daily intake (RDI) of dietary fiber.

\section{Materials and Methods}

\subsection{Source of Raw Materials}

The Wheat Flour (WF) used was commercial baker's grade wheat flour milled by Nigeria Flour Mills (Golden Penny, Nigeria), Margarine, Baker's brand of yeast; iodized salt and colorless granulated sugar were purchased from a local market in Lagos, Nigeria. Coconut and corn bran used were procured from a local market in Lagos. Cassava flour was also procured from the pilot plant of Federal Institute of Industrial Research Oshodi, Nigeria.

\subsection{Preparation of Coconut Flour}

Coconut fruits were sorted and processed to extract coconut milk and the resulting shaft/residue was washed thoroughly with boiling water to enhance complete removal of milk and oil from the shaft. It was drained, dried and ground using a grinder (model HL 3294/C Phillips) to obtain fine flour.

\subsection{Preparation of Corn Bran}

Corn bran can be processed and bought independently from grain processors. In this study, food grade dried corns were purchased from a local market (Lagos, Nigeria) and were dehulled to obtain bran devoid of germ and endosperm. The bran was milledusing a grinder (model HL 3294/C Phillips) into fine flour.

\subsection{Preliminary Trials}

The bread was produced using straight dough bulk fermentation method using the recipe shown in Table 1. Baking trials were performed and baking formula was adjusted to establish the effects of the inclusion levels of each of the fibres sources.

From the preliminary work, the crude fibre content of the fibre sources were determined; corn bran $(\mathrm{CBN})$ and coconut flour (CCF) has $17 \%$ and $37.4 \%$ respectively. This was necessary to serve as a guide for the level of inclusion of the fibre sources to be used in the study.

The following inclusion levels were therefore considered; 5\% Corn bran inclusion (HPF); 10\% Corn bran inclusion (HFT); 5\% Coconut flour inclusion (CNF); 10\% Coconut flour inclusion (CTP) and Control (cassava wheat -composite bread) (HBC).

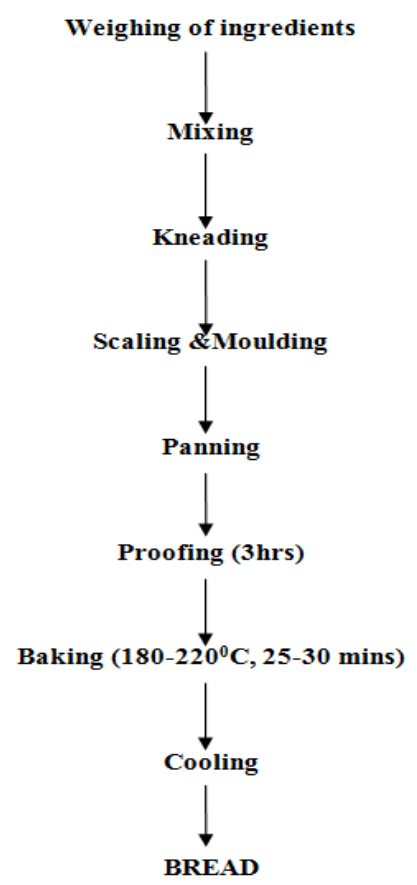

Fig. 1. Flow chart for the production of bread using a straight dough process. 
Table 1. Baking formula and conditions for the developed bread loaf.

\begin{tabular}{ll}
\hline Ingredients & Conditions \\
\hline Wheat flour (\%) & $85 \& 80$ \\
Cassava flour (\%) & 10 \\
Corn bran \& coconut flour (\%) & $5 \& 10$ \\
Dry yeast (\%) & 0.5 \\
Salt (\%) & 1.6 \\
Sugar (\%) & 10 \\
Water & Variable \\
Mixing time & $15-20 \mathrm{mins}$ \\
Proofing time & $3 \mathrm{hrs} @ 30-35^{\circ} \mathrm{C}$ \\
Baking time & $25-30$ mins @ $200-220^{\circ} \mathrm{C}$ \\
Relative humidity & $85 \%$ \\
\hline
\end{tabular}

*Ingredients listed as percent of flour

\subsection{Preliminary Evaluation of Baking Qualities of Bread Samples}

\subsubsection{Loaf Weight}

The loaf weight was determined by weighing the bread loaves after baking, using the laboratory scale (CE- 410I, Camry Emperors, China) and the readings recorded in grammes.

\subsubsection{Loaf Volume}

The loaf volume was determined by using Rape seed displacement method [15]. This was done by loading millet grains into an empty box with calibrated mark until it reached the marked level and unloaded back. The bread sample was put into the box and the measured millet was loaded back again. The remaining millet grains left outside the box was measured using measuring cylinder and recorded as loaf volume in $\mathrm{cm} 3$.

\subsubsection{Specific Volume}

The specific volume (volume to mass ratio) $\left(\mathrm{cm}^{3} / \mathrm{g}\right)$ was thereafter calculated.

$$
\text { Specific volume } \mathrm{cm} 3 / \mathrm{g}=\frac{\text { Loaf volume }}{\text { Loaf weight }}
$$

\subsubsection{Sensory Analysis}

Acceptance test to determine the level of acceptability based on the appearance/loaf shape, crust, crumb colour, chewability, taste, aroma, and overall acceptability was conducted using 9 point hedonic (Like extremely=9, Dislike extremely =1) scales [16]. The resulting data were analyzed using Analysis of Variance (ANOVA), and the means were separated using Duncan multiple range test, significance was accepted at $5 \%$ level of probability $(\mathrm{p}<0.05)$.

\subsubsection{Chemical Analysis}

The proximate parameters of the raw materials and bread samples were determined using analytical procedures [17]. Results were expressed as means of triplicate determinations.

\subsubsection{Statistical Analysis}

Results of the test bread samples were evaluated using SPSS version 16.0. Mean separation was carried out using Duncan Multiple Range test and Analysis of Variance ANOVA was conducted on the mean values to determine the significance of any differences between the samples.

Table 2. Bread making performance.

\begin{tabular}{llllll}
\hline PARAMETER & HPF & HFT & CNF & CTP & HBC \\
$\begin{array}{l}\text { Optimum water addition in } \\
\text { flour blends (ml) }\end{array}$ & 660 & 675 & 700 & 720 & 640 \\
Optimum mixing time(min) & 20 & 20 & 20 & 20 & 15 \\
Scaled dough(g) & 250 & 250 & 250 & 250 & 250 \\
Proof time(min) & 180 & 180 & 180 & 180 & 180 \\
Baking time (min) & 25 & 25 & 25 & 25 & 25 \\
\hline
\end{tabular}

KEY: HPF -5\% Corn bran; HFT- 10\% Corn bran inclusion; CNF --5\% Coconut fibre, CTP-- 10\% Coconut fibre inclusion, HBC--- Control sample

\section{Results \& Discussion}

\subsection{Effect of Fibre Inclusion on Physical Characteristics of Developed Bread}

Figures 2, 3, and 4 show the effect of inclusion levels of corn bran $(\mathrm{CBN})$ and coconut flour $(\mathrm{CCF})$ on the physical characteristics i.e loaf weight, loaf volume and specific loaf volume of the test bread samples.

Loaf weight is determined by the quantity of dough baked and the amount of moisture and carbon dioxide $\mathrm{CO}_{2}$ diffused out and since fibre is a highly water- binding macromolecules that compete with starch and other flour ingredients for water.

Loaf weights of bread differ significantly $(p>0.05)$ with increased fibre inclusion. The values ranged from $241 \mathrm{~g}-$ $249 \mathrm{~g}$ with the highest value $(249 \mathrm{~g})$ obtained from $10 \% \mathrm{CBN}$ inclusion and the lowest value $(241 \mathrm{~g})$ was found in bread prepared without fibre inclusion (HBC). Increase in loaf weight may be attributed due to the increase in water addition in flour blends as was recorded in table 2. This additional water is retained in the baked loaf thereby, resulting in heavier loaves.

Loaf volume is regarded as the most important bread characteristic because it provides a quantitative measurement of baking performance. It is a good measurement of protein quality. The loaf volume of developed bread samples decreased with increased level of fibre inclusion. Significant reduction $(p<0.05)$ was observed in the loaf volume of the bread from $5 \%$ to $10 \%$ fibre inclusion. Decrease in loaf volume of bread with increased level of fluted pumpkin flour and mushroom powder have also been reported [18, 19].The decrease in loaf volume of bread may be attributed to the dilution effect on the gluten network thereby reducing the gluten strength with a ripple effect of poor carbon dioxide gas formation and retention in the baked dough.

Specific volume for control bread was $5.26 \mathrm{~cm}^{3} / \mathrm{g}$. The results of the specific volume of bread found in this study indicated that there was a substantial decrease in the specific volume of bread at increased level of fibre inclusion. It ranged from 5.02-5.77 with highest value obtained from 5\% CCF inclusion and the lowest value from $10 \%$ corn bran inclusion. However, the value obtained was within the range specified by Standard Organization of Nigeria (SON) standards for bread. The results obtained from this study is in agreement with the results reported by [20] who also reported 
a decreasing trend in specific volume of bread incorporated with Oat, Psyllium and Barley Fibers

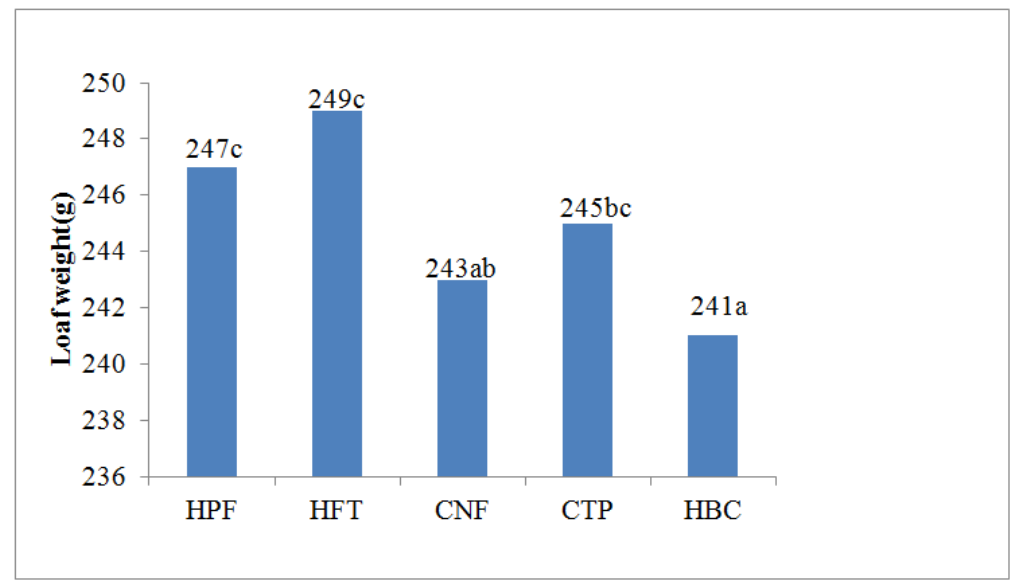

Fig. 2. Effect of fibre inclusion on loaf weight of test bread samples .

KEY: HPF -5\% Corn bran; HFT- 10\% Corn bran inclusion; CNF --5\% Coconut fibre, CTP-- 10\% Coconut fibre inclusion, HBC--- Control sample.

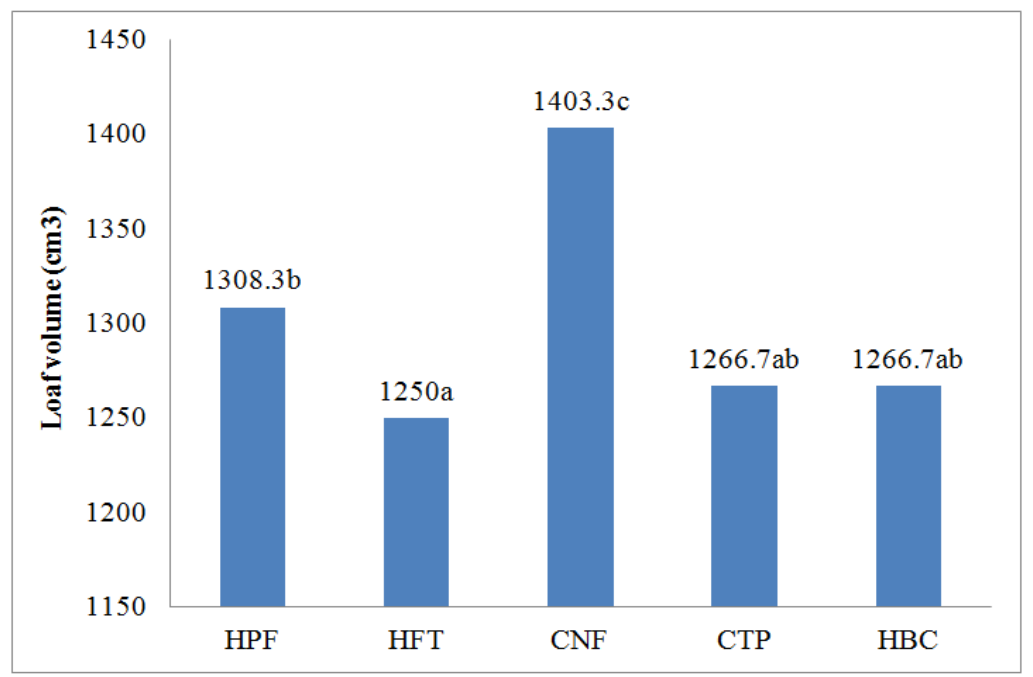

Fig. 3. Effect of fibre inclusion on loaf volume of test bread samples .

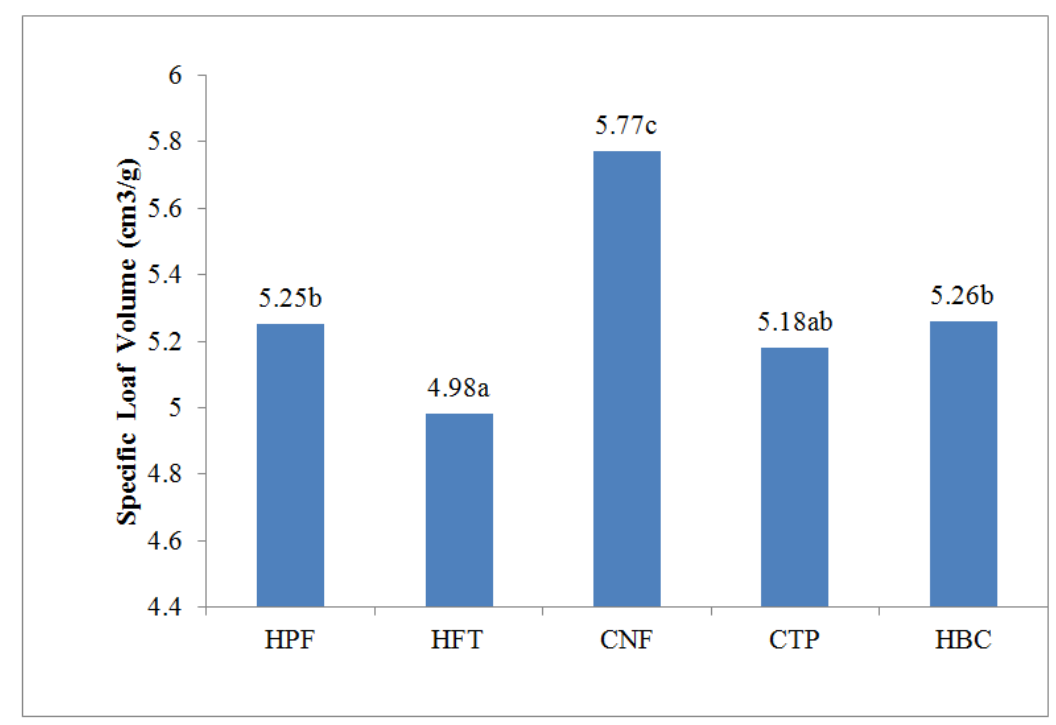

Fig. 4. Effect of fibre inclusion on specific volume of test bread samples.

KEY: HPF -5\% Corn bran; HFT- 10\% Corn bran inclusion; CNF --5\% Coconut fibre, CTP-- 10\% Coconut fibre, HBC--- Control sample 


\subsection{Effect of Fibre Inclusion on the Chemical Composition of Developed Bread}

Results for chemical composition indicated that there were significant differences $(p<0.05)$ in crude protein and dietary fibre contents of the bread samples at the levels of fibre inclusion studied (Table 3). The dietary fibre content of the bread loaves increases significantly $(\mathrm{p}>0.05)$ as the level of fibre inclusion increases. It ranged from 3.79 to $5.28 \%$ with the highest value in $10 \%$ coconut fibre bread (CTP) and lowest in 5\% corn bran fibre bread (HPF). However, result indicated that corn bran fibre bread had lower dietary fibre contents of 3.79 and $3.98 \%$ compared to the control sample (4.56\%). This might probably due to interaction between the fiber components of corn bran and other dough ingredients. It was observed that from the study that coconut enriched bread with dietary fibre of $5.28 \%$ was able to deliver $21.12 \%$ of the
Recommended Daily Intake (RDI).

The crude protein content of the fibre enriched bread samples ranged from 4.56 to $5.15 \%$ while the control sample had $4.69 \%$. It increased significantly with increasing levels of fibres inclusion.

Significant reduction existed $(\mathrm{p}<0.05)$ in the moisture content of the fibre enriched bread from 5 to $10 \%$ level of inclusions studied. It ranged from 30.44 to $33.48 \%$ with the highest value in control sample (HBC) non fibre bread and lowest in $10 \%$ coconut fibre bread (CTP). This is attributed to high water binding property of the added fibre.

The dry matter content of the bread sample showed significant increase as the level of fibre inclusion increased. It ranged from 66.52 to $69.56 \%$ with the highest value in $10 \%$ CCF fibre bread (CTP) and lowest in control sample i.e non fibre bread (HBC).

Table 3. Chemical composition of the developed bread samples.

\begin{tabular}{llllllll}
\hline Sample code & \%Crude Protein & \%Ether Extract & \% Ash & \%Crude Fiber & \%Dry Matter & \%Moisture & \%Dietary Fiber \\
\hline HPF & $5.15 \mathrm{a}$ & $0.50 \mathrm{a}$ & $0.65 \mathrm{~b}$ & $0.06 \mathrm{a}$ & $67.30 \mathrm{a}$ & $32.70 \mathrm{a}$ & $3.98 \mathrm{a}$ \\
HFT & $4.62 \mathrm{c}$ & $0.50 \mathrm{a}$ & $0.66 \mathrm{~b}$ & $0.06 \mathrm{a}$ & $66.98 \mathrm{ab}$ & $33.02 \mathrm{a}$ & $.79 \mathrm{~d}$ \\
CNF & $4.56 \mathrm{~d}$ & $0.41 \mathrm{c}$ & $0.66 \mathrm{~b}$ & $0.05 \mathrm{a}$ & $66.61 \mathrm{~b}$ & $33.39 \mathrm{c}$ & $4.85 \mathrm{~b}$ \\
CTP & $5.01 \mathrm{~b}$ & $0.47 \mathrm{~b}$ & $0.15 \mathrm{a}$ & $0.07 \mathrm{a}$ & $69.56 \mathrm{c}$ & $30.44 \mathrm{~b}$ & $5.28 \mathrm{c}$ \\
HBC & $4.69 \mathrm{e}$ & $0.44 \mathrm{~d}$ & $1.00 \mathrm{c}$ & $0.05 \mathrm{a}$ & $66.52 \mathrm{~b}$ & $33.48 \mathrm{c}$ & $4.56 \mathrm{e}$ \\
\hline
\end{tabular}

Means values in the same column with the same letter are not significantly different $(\mathrm{p}<0.05)$.

KEY: HPF -5\% Corn bran; HFT- 10\% Corn bran inclusion; CNF --5\% Coconut fibre, CTP-- 10\% Coconut fibre, HBC--- Control sample

\subsection{Sensory Evaluation}

The web diagram for mean sensory scores of developed bread loaves showed that bread produced from $5 \%$ coconut fibre bread (CNF) had the highest score for all the attributes tested (fig 5). This was followed by the bread sample from $10 \%$ inclusion (CTP). The overall acceptability of the bread samples also followed the same trend and all the bread samples were acceptable.

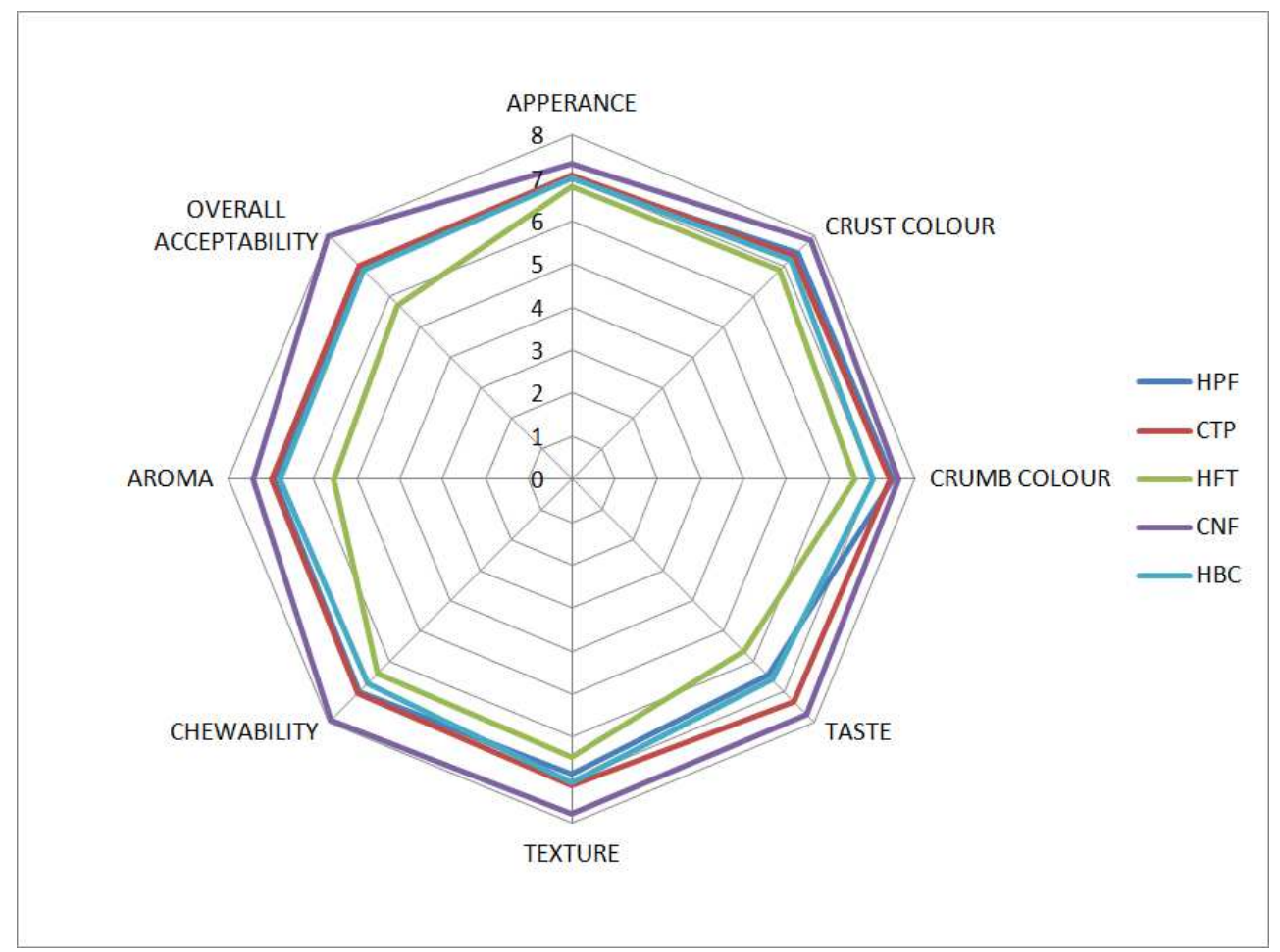

Fig. 5. Web Diagram for Mean Sensory Scores of Developed Bread Loaves. 


\section{Conclusions}

The outcome of the research showed that acceptable fibreenriched bread can be developed using coconut and corn bran flour.

The effect of incorporation of coconut and corn bran flours at 5 and $10 \%$ level of inclusion on the bread baking revealed increased loaf weight and decreased specific loaf volume of the developed bread.

Also, experimental evidence showed that increasing level of inclusion of fibre sources, there was a significant increase $(p<0.05)$ in the dietary fibre and protein content of the developed bread. The study therefore, revealed that enriching bread with coconut flour at 5 and $10 \%$ levels of inclusion increased the dietary fibre content from $4.56 \%$ to $4.85 \& 5.28 \%$ respectively and this translates to $21.12 \%$ \& $19 \%$ of dietary Fibre recommended daily intake, which makes the work worthwhile in order to augment other food sources of dietary fibre to meet the recommended daily intake.

Generally, this study demonstrated the potential of incorporating coconut flour and corn bran flour into bread, and possibly other baked food products, thereby creating opportunity for food producers to provide more healthy dietary fibre enriched products.

\section{Acknowledgements}

The authors wish to express their sincere gratitude to the Director General and Management of Federal Institute of Industrial Research Oshodi Lagos, Nigeria for providing funds and facilities for this research work.

\section{References}

[1] Chen, M. F. (2011). The mediating role of subjective health complaints on willingness to use selected functional foods. Food Qual. Pref., 22: 110-118.

[2] Mendis, E. and Kim, S. K. (2011). Present and future prospects of seaweeds indeveloping functional foods. In: Advances in Food and Nutrition Research,Se-Kwon, K. (ed.). Academic Press, p1-15.

[3] DeVries J.W; (2010); Validation official methodology commensurate with dietary fibre research and definitions: In J.W. van der Kamp, J Jones, B.McCleary\& D. Topping[Eds]; Dietary Fibre: New frontiers for food and health (pp 29-48) Wageningen,. The Netherlands; Wageningen Academic Publishers.

[4] Trinidad, P.T., Mallillin, A.C., Valdez, D.H., Loyola, A.S., Askali-Mercado, F.C., Castillo, J.C., Encabo, R.R., Masa, D.B., Maglaya, A.S. and Chua, M.T. (2006), Dietary fiber from coconut flour: A functional food. Innovative Food Science and Emerging Technologies, 7: 309-317.

[5] Ajila, C.M., PrasadaRao,U.J.S;( 2013); Mango peel dietary fibre; Composition and associated bound phenolics. Journal of Functional Foods 5, pp 444-450

[6] O'Shea, N., Arendt, E.K., Gallagher E (2012): Dietary fibre and phytochemical characteristics of fruit and vegetables byproducts and their recent application as novel ingredients in food products. Innovative Food Science and Emerging Technologies 16.pp 1-10

[7] Drzikova, B., G. Dongowski, et al. (2005). "Dietary fibre-rich oat-based products affect serum lipids, microbiota, formation of short-chain fatty acids and steroids in rats." BrJ Nutr 94(6): 1012-1025.

[8] Cho,S.S., Prosky.L., Dreher,M L (1999);Complex carbohydrate in foods: CRC Press 676,

[9] Nelson A. L (2001): High fibre ingredients Eagan press handbook series. St Paul, MN, Eagan Press.

[10] Rodriguez-Ambriz, S. L., Islas-Hernandez, J. J., AgamaAcevedo, E., Tovar, J., and Bello-Perez, L A. (2008). Characterization of a fibre rich powder prepared by liquefaction of unripe banana flour.Food Chemistry, 107, $1515-1521$.

[11] Anyika, J.U. and A.C. Uwaegbute, (2005). Frequency of consumption and nutrient content of some snacks eaten by adolescent secondary and University student in Abia State. Nig. J. Nutr., Sci., 26: 10-15.

[12] RamaswamyLalitha, (2014). Coconut flour: A low carbohydrate, gluten free flour: International Journal of Ayurvedic and herbal medicine 4:1, 1426-1436

[13] Trinidad, P.T., Divinagracia, H.V., Aida, C.M., Faaridah, C.A., Angelica, S.M., Modesto, T.C., Askali, C.A., Loyola, A.S. and Masa, D.B. (2001). Coconut flour from residue: Agood source of dietary fibre. Indian Coconut Journal, XXXII (6), 9-13.

[14] Fife (2005) Cooking with coconut flour, A Delicious Low Carb, Gluten free Alternative to Wheat".

[15] AACC, (2000) International. Approved methods of the American Association ofAssociation of Cereal Chemists. St Paul, MN (USA): American Association of Cereal Chemists.

[16] Iwe, M.O (2002). Handbook of Sensory Methods and Analysis. Rojoint Communication Services Ltd, Uwani-Enugu Nigeria

[17] AOAC (2010). Official methods of analysis.Association of Official Analytical Chemists.18th edition.Washington D. C. USA.

[18] Agu, H.O., J.A. Ukonze and K.A. Paul, (2010). Quality characteristics of bread made from wheat and fluted pumpkin seed flour. Nig. Food J., 28: 188-198.

[19] Okafor, J.N.C; Okafor G.I; Ozumba, A.U and. Elemo G.N (2012): Quality Characteristics of Bread Made from Wheat and Nigerian Oyster Mushroom (Pleurotusplumonarius) Powder Pakistan Journal of Nutrition 11 (1): 5-10, 2012.

[20] Bhise, S.R., \&Kaur.A (2014): Incorporation of Oat, Psyllium and Barley Fibers: Effect on Baking Quality, Sensory Properties and Shelf Life of Bread. International Journal of Engineering Practical Research (IJEPR) Volume 3 Issue 3, 5258, August 2014. Doi:10.14355/ijepr.2014.0303.02 